ERRATUM

Riitta Ojala $\cdot$ Marja Ala-Houhala $\cdot$

Aimo P. T. Harmoinen - Tiina Luukkaala •

Jukka Uotila $\cdot$ Outi Tammela

\title{
Tubular proteinuria in pre-term and full-term infants
}

Published online: 20 July 2006

(C) IPNA 2006

The online version of the original article can be found at: http://dx. doi.org/10.1007/s00467-005-2028-0.

R. Ojala $(\bowtie) \cdot$ M. Ala-Houhala $\cdot$ O. Tammela Department of Pediatrics, Tampere University Hospital, P.O. Box 2000, 33521 Tampere, Finland e-mail: riitta.ojala@pshp.fi

Tel.: +358-3-3116111

Fax: $+358-3-2475314$

J. Uotila

Department of Gynecology, Tampere University Hospital, Tampere, Finland

R. Ojala

Pediatric Research Center, Tampere University Hospital, Tampere, Finland

\section{A. P. T. Harmoinen}

Department of Clinical Chemistry,

Savonlinna Central Hospital,

Savonlinna, Finland

T. Luukkaala

School of Public Health Research Unit,

Tampere University Hospital,

Tampere, Finland

\section{Pediatr Nephrol (2006) 21:68-73}

There is an error in the first paragraph of the Results section of this manuscript. The correlation between first urinary alpha $1-\mathrm{M} /$ creatinine ratio and gestational age (line 6) should be read -0.647 .

The authors apologize for this error. 